\title{
A Review on Azelaic Acid Emulgel for Acne and Hyperpigmentation
}

\author{
Halpati Hemangini Amrutbhai* ${ }^{1}$, Patel Ankita Jaykumar*², Narkhede Sachin B.*3 \\ ${ }^{1 *}$ Smt. B.N.B Swaminarayan Pharmacy College, M.Pharm, Department of Pharmaceutics, M.pharm, \\ Gujarat India. \\ ${ }^{2 *}$ Smt. B.N.B Swaminarayan Pharmacy College, Department of Pharmaceutics, Assistant Professor, \\ Gujarat India. \\ 3*Principle, Smt. B.N.B Swaminarayan Pharmacy College, Assistant Professor, Gujarat India. \\ hemanginihalpati0008@gmail.com ${ }^{* 1}$
}

\begin{abstract}
Acne is a very common inflammatory skin disease also known as Pimples. Pimples are commonly found on face, chest, upper back and neck. Propionibacterium and Staphylococcus aureus (S. aureus) are responsible for acne they are mainly present in Sweat gland. Azelaic acid is anti-keratinizing, antibacterial and anti-inflammatory drug. Azelaic Acid is mainly act on cellular protein synthesis in both aerobic and anaerobic bacteria and it reducing the proliferation of Propionibacterium. Azelaic acid is used to treat acnes as well as Hyperpigmentation and it also reduce inflammation and redness. But Azelaic Acid is Hydrophobic drug low soluble and low permeable so The Aim of present study was to Enhance Permeability and Solubility of Azelaic Acid by Formulating Emulgel For effective treatment of Acne and Hyperpigmentation.
\end{abstract}

Keyword: Acne, Hyperpigmentation, Hydrophobic drug, Azelaic Acid, Emulgel.

\section{INTRODUCTION}

\subsection{Introduction to Acne}

The word acne may be derived from the Greek work "achne" that means efflorescence.

Acne is used for plugged pores which is whiteheads and blackheads, pimples, and even deeper nodules and deeper cysts which is occur on face, back, shoulders, neck (nape), and chest and on upper arms ${ }^{[1]}$. Acne is a skin problem caused by alteration in the pilosebaceous gland. Acne is very common during adolescence that affect $85 \%$ teenagers, and continues into adulthood. At starting stage acne exhibit as mild acne and converted into moderate acne vulgaris. Mostly acne lesions are observed as inflammatory papules, pustules and nodules, when nodules become large it is called as "cysts" and nodulocystic term has been used for explain inflammatory acne vulgaris ${ }^{[2]}$.

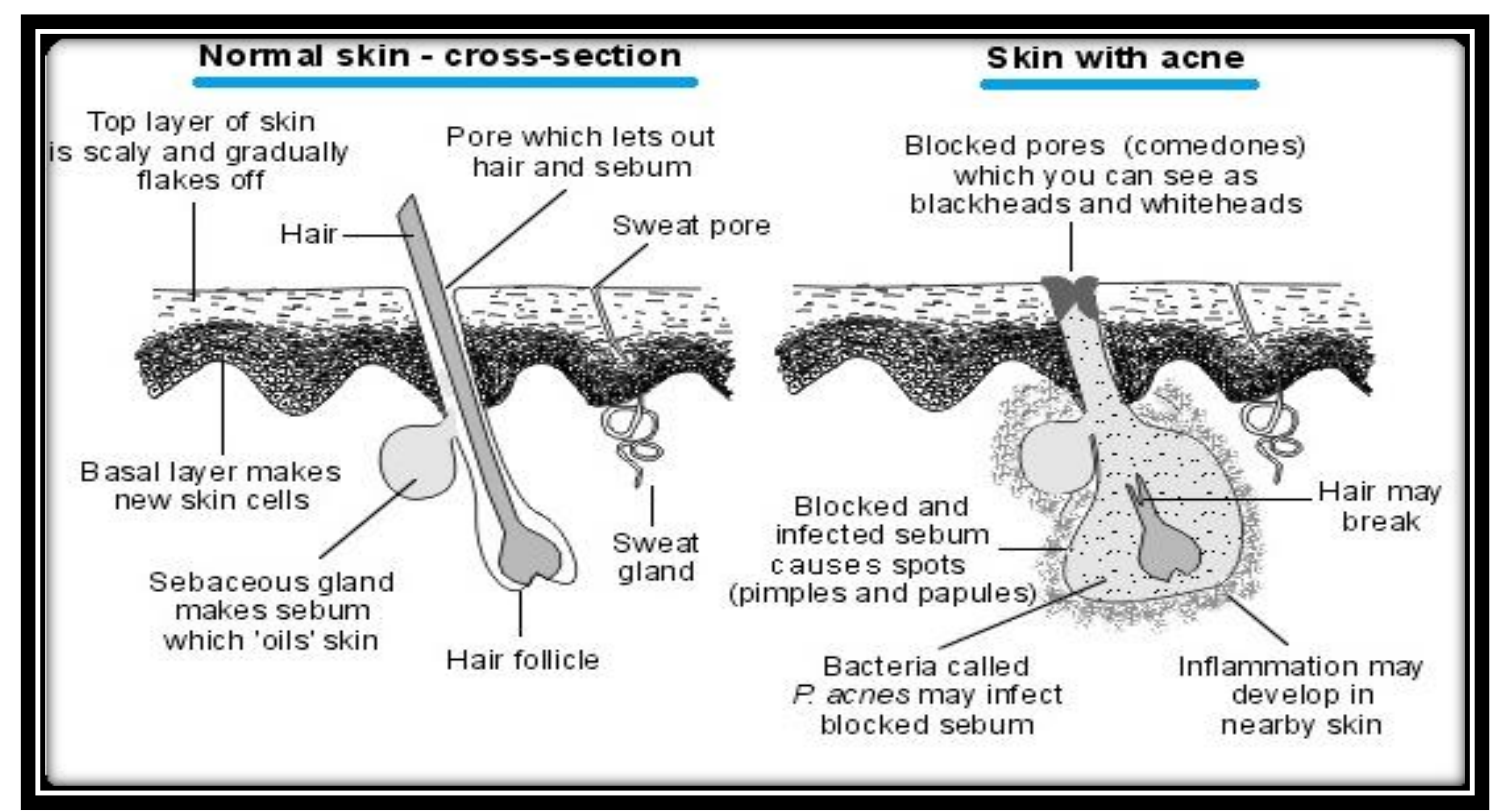

Figure No.1 Cross-section of Normal skin and Acne skin 


\subsubsection{Types of Acne}

\section{Table No.1Types of Acne}

\begin{tabular}{|c|c|c|}
\hline \multirow[t]{2}{*}{$\begin{array}{l}\text { Non- } \\
\text { inflammatory } \\
\text { Acne: } \\
\text { It do not cause } \\
\text { swelling }\end{array}$} & Whiteheads & $\begin{array}{l}\text { Whiteheads are generate from pore and blocked pore } \\
\text { completely. It contain oil, microorganisms, and dead } \\
\text { cells of skin that result in a white head on the skin } \\
\text { surface }{ }^{[3]} \text {. }\end{array}$ \\
\hline & Blackheads & $\begin{array}{l}\text { Partially blocking of pores resulting into blackheads. It } \\
\text { contain bacteria, sebum, and dead cells of skin that } \\
\text { slowly moves towards the surface of the skin and } \\
\text { blackhead is form. Reaction of melanin with oxygen } \\
\text { species is Responsible for darker color of black head }{ }^{[3]} \text {. }\end{array}$ \\
\hline \multirow[t]{7}{*}{$\begin{array}{l}\text { Inflammatory } \\
\text { acne }\end{array}$} & Papules & $\begin{array}{l}\text { It is Red, inflamed and bumps like structure present on } \\
\text { skin without head is known as papules. Squeezing of } \\
\text { papule will cause scarring }{ }^{[3]} \text {. }\end{array}$ \\
\hline & Acne Conglobata & $\begin{array}{l}\text { Higher severity of acne vulgaris leads to acne } \\
\text { conglobata which result into interconnected large } \\
\text { lesions. It may contain Blackheads. In males it is } \\
\text { present between } 18 \text { and } 30 \text { years old }{ }^{[4]} \text {. }\end{array}$ \\
\hline & Acne Fulminant & $\begin{array}{l}\text { The starting stage of acne conglobata is known as acne } \\
\text { fulminans. Acne fulminans is characterized by joints } \\
\text { aching and a fever. It can be treated with oral steroids } \\
\text { and/ or Accutane }{ }^{[4]} \text {. }\end{array}$ \\
\hline & Gram-Negative Folliculitis & $\begin{array}{l}\text { It is bacterial infection which contain pustules and cysts } \\
\text { caused by gram-negative folliculitis }{ }^{\left[{ }^{[}\right]} \text {. }\end{array}$ \\
\hline & Pustules: & $\begin{array}{l}\text { Pustules are appear on skin as a red inflamed circle that } \\
\text { contain white or yellow at Centre }{ }^{[5]} \text {. }\end{array}$ \\
\hline & $\begin{array}{l}\text { Pyoderma } \\
\text { (Rosacea } \\
\text { Fulminans): }\end{array}$ & $\begin{array}{l}\text { It is mainly observed in females. It is larger nodules } \\
\text { that are painful, pustules and sores. It's suddenly started } \\
\text { and only presents on face. It can be treated by Accutane } \\
\text { and corticosteroid injections }{ }^{[5]} \text {. }\end{array}$ \\
\hline & Nodules: & $\begin{array}{l}\text { When acne is progress and result in to Severe acne } \\
\text { known as nodules. It is hard bump within skin which } \\
\text { become large last for month }{ }^{[5]} \text {. }\end{array}$ \\
\hline
\end{tabular}




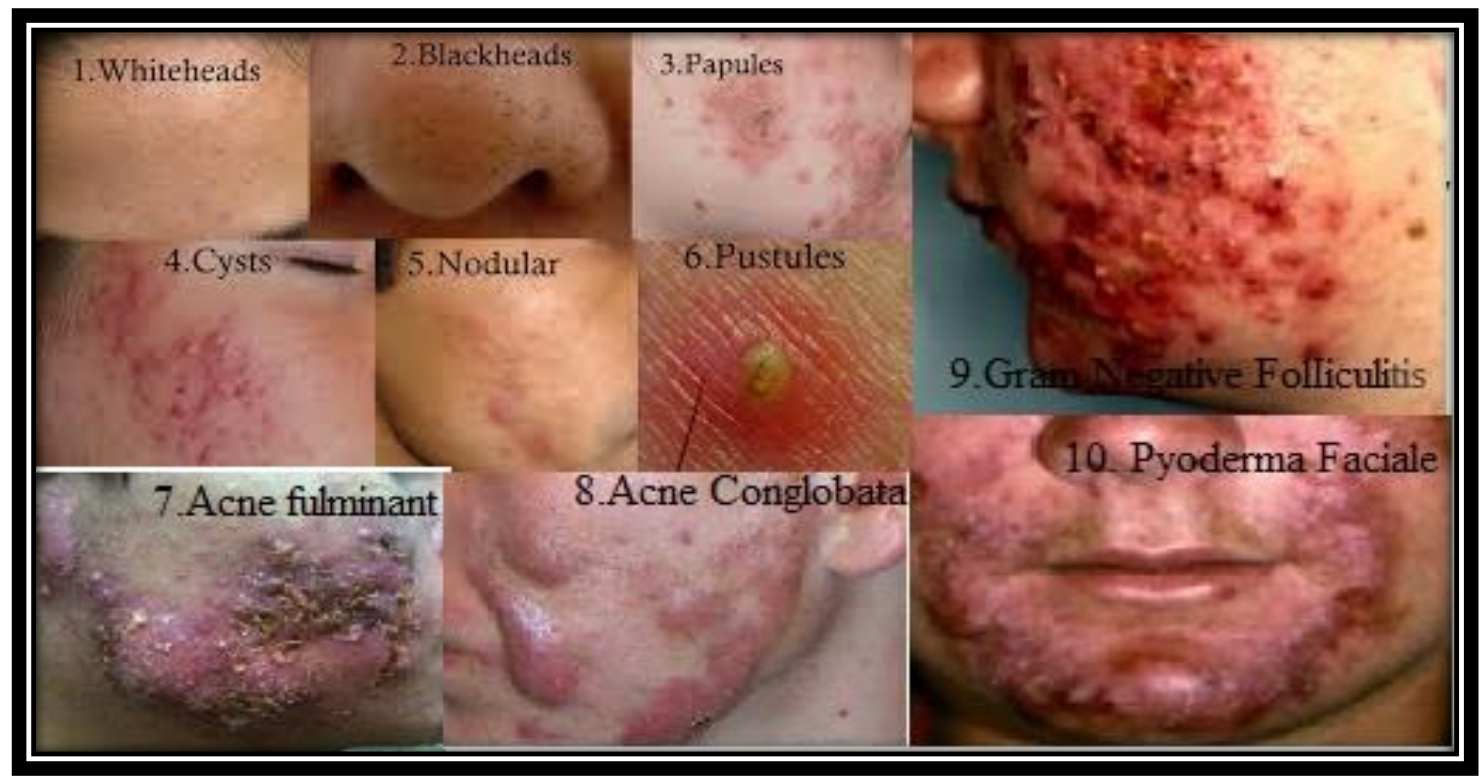

1.2 Hyperpigmentation

_Figure No.2. Difference types of Acne

Pigmentation or skin color is depend on amount and distribution of epidermal melanin. Formation of melanin is done by melanocytes. Melanocytes are presents in the basal layer of the epidermal layer.

Melanin are classified mainly into two types:
Eumelanin
Pheomelanin

Individuals having darker skin contain higher amount of melanin and having high amount of eumelanin ${ }^{[6,}$ 7].

\subsubsection{Type of Hyperpigmentation}

Table No.2 Types of Hyperpigmention.

\begin{tabular}{|c|c|}
\hline Postinflammatory hyperpigmentation & $\begin{array}{l}\text { Dark skin occurs after injury or an inflammatory } \\
\text { eruption. } \\
\text { *njury such as psoriasis, eczema, acne, trauma }{ }^{[6]} \text {. }\end{array}$ \\
\hline Maturational dyschromia & $\begin{array}{l}\text { Darkening of facial skin especially dark skin of } \\
\text { cheeks and pigmentation on forehead due to sun } \\
\text { exposure }{ }^{[6]} \text {. }\end{array}$ \\
\hline Riehl melanosis & $\begin{array}{l}\text { Brown-grey color is deposited into dermis. It is due to } \\
\text { use of cosmetics }{ }^{[6]} \text {. }\end{array}$ \\
\hline Melasma & $\begin{array}{l}\text { Distribution of dark brown and light patches present } \\
\text { as irregular borders due to hormonal therapy, } \\
\text { pregnancy, such as oral contraceptives, and intense sun } \\
\text { exposure }{ }^{[7]} \text {. }\end{array}$ \\
\hline Exogenous ochronosis & $\begin{array}{l}\text { Banana - shaped and yellow-brown spots are deposits } \\
\text { in the dermis due to more use of hydroquinone }{ }^{[7]} \text {. }\end{array}$ \\
\hline Acanthosis nigricans & $\begin{array}{l}\text { Diabetics and/or obesity patient have symmetric or } \\
\text { velvety patches on neck }{ }^{[7]} \text {. }\end{array}$ \\
\hline Dermatosis papulosa nigra & * To 5-mm pigmented papules especially on forehead. \\
\hline Naevus of Ota & $\begin{array}{l}\text { At the puberty age Blue-grey color macules of } \\
\text { millimeter size is observed. }\end{array}$ \\
\hline Hori naevi & $\begin{array}{l}\text { * Blue-grey to grey-brown macules are found on the } \\
\text { zygomatic area, upper eyelids, on the forehead, and } \\
\text { root and alae of the nose. }\end{array}$ \\
\hline Ephelides & $\begin{array}{l}\text { Oval or irregular and round shape } 1-3-\mathrm{mm} \\
\text { hyperpigmented macules }{ }^{[7]} \text {. }\end{array}$ \\
\hline
\end{tabular}




\begin{tabular}{|l|c|}
\hline Erythema dyschromicum perstans & $* \begin{array}{l}\text { Grey to blue-brown inflammatory Patches Distributed } \\
\text { on non-sun-exposed areas }{ }^{[7]} .\end{array}$ \\
\hline Actinic lichen planus & $*$\begin{tabular}{l} 
Violaceous fine scale lesions are Photodistributed. \\
\hline Lichen planus
\end{tabular}$\quad \begin{array}{l}\text { Pigmented Oval shaped or irregular shaped grey- } \\
\text { brown to brown macules are observed in sun-exposed } \\
\text { areas }{ }^{[7} .\end{array}$ \\
\hline Periorbital hyperpigmentation & $* \begin{array}{l}\text { Infraorbital pigmentation or dark circles are observed } \\
\text { because of genetics. }\end{array}$ \\
\hline
\end{tabular}

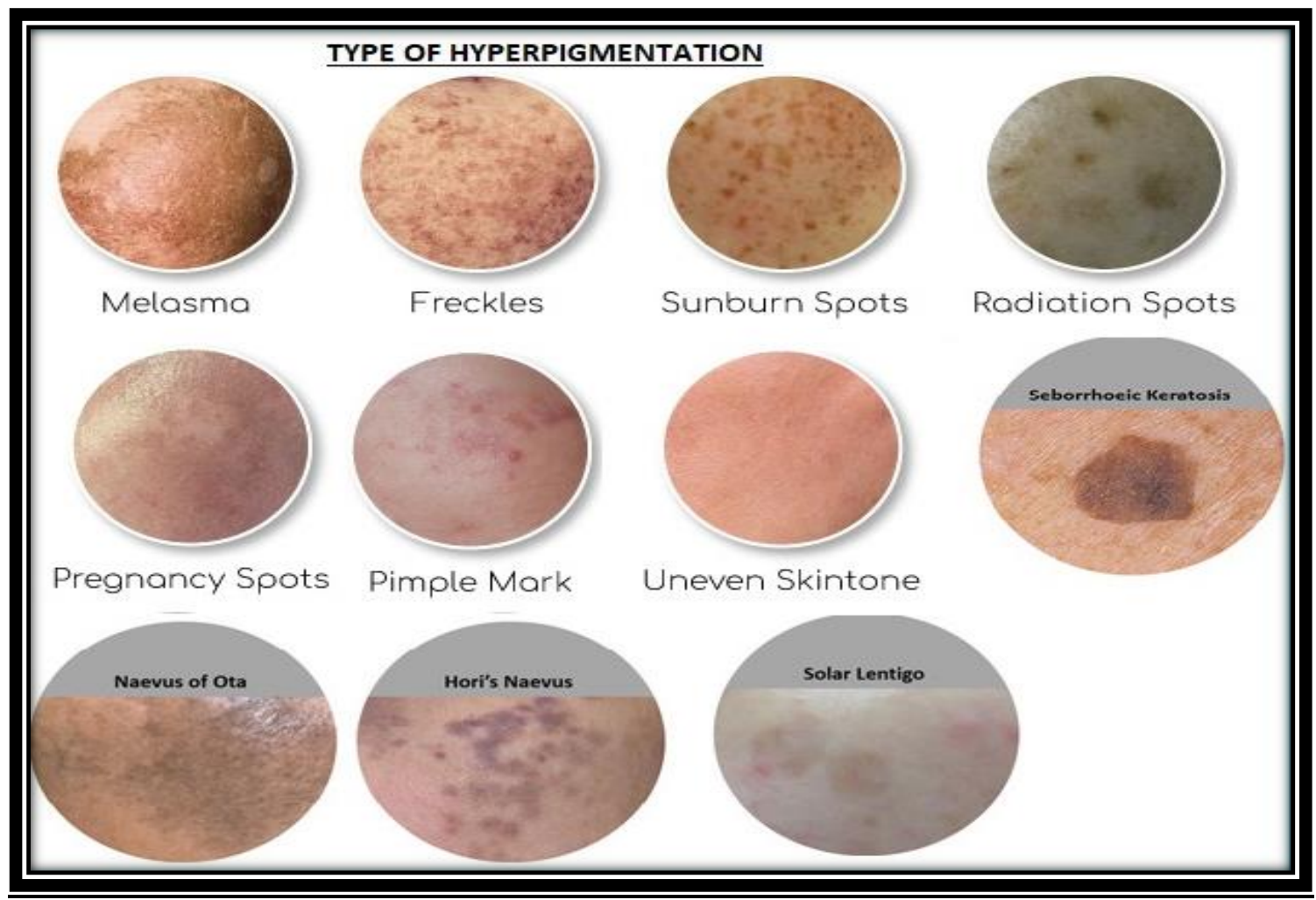

Figure No.3. Types of Hyperpigmentation.

\subsection{Introduction to Emulgel delivery system $^{[8]}$}

Topical drug delivery is easy administration of drug in the body through rectal, ophthalmic, vaginal and skin. Avoid first pass metabolism is main advantage of topical delivery system. it also help to avoid risk of intravenous inconveniences and other factors such as like gastric emptying, presence of enzymes, $\mathrm{pH}$ changes ${ }^{[8]}$.

Gels are consist of large amount of water or hydro alcoholic liquid. But it is not able to enhance penetration so to enhance penetration emulsion is best choice. Emulsion having stability issue which should be avoid by incorporating emulsion in to gel. Combination of Emulsion and Gel is known as Emulgel. Emulgels have several favourable properties such as greaseless, bio-friendly, transparent, pleasing appearance,easily spreadable, easily removable, thixotropic, emollient, watersoluble, non-staining, and longer shelf life ${ }^{[8]}$. 1.3.1 Need for Emulgel

Acne vulgaris is one of the most common chronic skin diseases. Initiating stage of mild Acne is progressively convert into Acne Vulgaris, There are lots of treatment available for acne as mentioned above. But after the treatment affected area is results in to Scars, and pigmented skin. This pigmented skin is one type of symptoms of Hyperpigmentation, which is known as Post Acne hyperpigmentation. To treat both, 
Acne and Hyperpigmentation Azelaic acid is effective drug. In several trial it has been reported that Azelaic acid does not elict Bacterial resistance and fewer side effect than other anti-acne agent. But Azelaic Acid is Class IV drug Low permeability and solubility to overcome this problem Emulgel will be excellent choice as Novel drug approach.

\subsubsection{Ingredients used in the Formulation} of Emulgel ${ }^{[9]}$

1) Aqueous phase: it is responsible of swelling purpose of gelling agent. The most commonly used aqueous phase are water, alcohol ${ }^{[9]}$.

2] Oil phase:

* Selection of oil phase done by optimizing its effects on the viscosity, permeability, drug release, emulsification and stability for the preparation in oil phase of the emulsion, used for the solubility of hydrophobic drugs. It can also be selected as per the effect of active molecule that gives synergistic effect as various oils had medicinal value ${ }^{[9]}$.

* The most commonly used oil phases are :

$>$ Mineral oils liquid paraffin

$>$ Propylene glycol

$>$ Isopropyl myristate

$>$ Isopropyl palmitate

$>$ Castor oil

$>$ Olive oil

$>$ Balsam oil

$>$ Wool wax

$>$ Soybean oil

$>$ Cotton seed oil

$>$ Oleic acid

$>$ Maize oil

$>$ Arachis oil

\section{3] Emulsifiers:}

* They are utilize for the emulsification and stability purpose of the formulation by decreasing the interfacial tension.

* Selection is based on proper hydrophilic and lipophilic balance (HLB) for example the surfactant with HLB value greater than 8 is used in oil in water emulsion where as the surfactant with HLB value less than 8 are used in water in oil emulsion ${ }^{[9]}$.

* Tween are applicable for the water phase while the spans are applicable for the oil phase for emulsification.
- Mixture of tween and span provide better stability than single.

$>$ Labrasol

$>$ Polyethylene glycol

> Polyoxyethylene sorbitan monooleate (Tween 80)

$>$ Sodium stearate

$>$ Sorbitan monooleate (Span 80)

$>$ Stearic acid

4] Gelling agent:

* May be of natural, synthetic source; selection of these polymers can be based on the multifunction as thickening and acting as emulsifying agents.

* They are incorporated to make the system thixotropic.

* Effect of gelling agent on the drug release pattern should be studied.

* Synthetic polymer :

$>$ Carbopol.

$>$ Carboxymethylcellulose

$>$ Carboxyvinyl polymers,

$>$ Hydroxyethylcellulose,

$>$ Hydroxypropylmethylcellulose,

$>$ Magnesium aluminum silicates

$>$ Methylcellulose,

* Natural materials

$>$ Tragacanth

$>$ Carrageen

$>$ Pectin,

$>$ Agar,

$>$ Xantham gum,

$>$ Alginic acid

$>$ starch

5] Penetration Enhancers:

* These are agents that penetrate into and interact with skin constituents to induce a temporary and reversible increase in skin permeability.

* Use of Penetration enhancers :
$>$ Cinnamon
$>$ Clove oil
$>$ Isopropyl myristate
$>$ Lecithin
$>$ Linoleic acid
$>$ Menthol
$>$ Oleic acid
$>$ Urea

1.3.3 Method of Preparation

STEP1: Formulation of gel base

The gel is formulated by addition of Carbopol 934 Polymer in Purified Water with continuous stirring at moderate speed. 


$$
\text { E-ISSN: 2321-9637 }
$$

\section{Available online at www.ijrat.org}

STEP2: Formulation of Emulsion either O/W

Oil phase is consist of Span 80 in Isopropyl myristate and aqueous phase is consist of tween 80 in purified water, Methyl Paraben and Propyl Paraben. Drug is dissolved in propylene glycol and added in oil phase. Both phases are separately heated on water bath at $70^{\circ}-80^{\circ} \mathrm{C}$. Oil phase is added in aqueous phase with continuous stirring at Room temperature ${ }^{[9]}$.

STEP3: Formulation of Emulgel

Incorporation of emulsion into gel base with continuous stirring

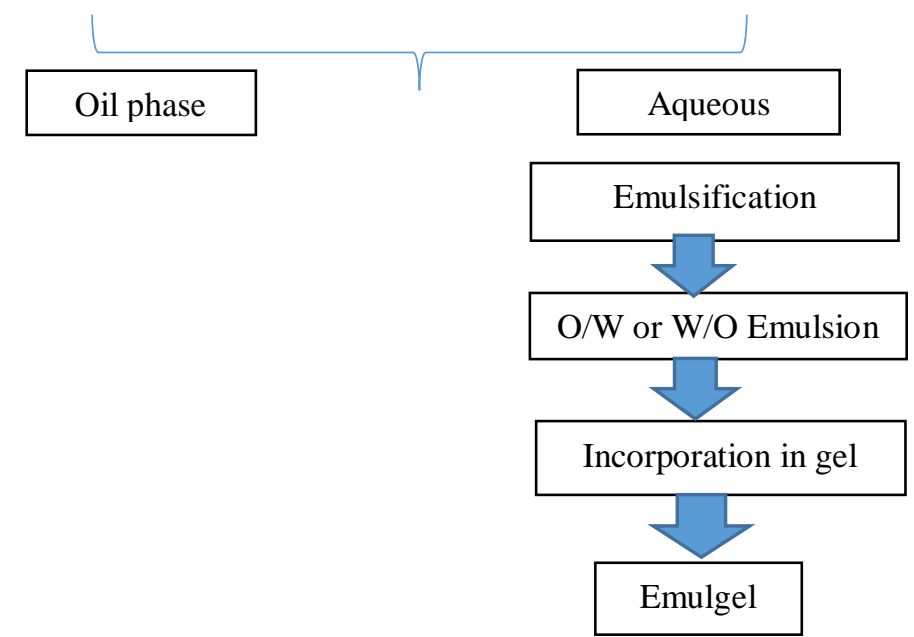

1.3.4 Property of Emulgel ${ }^{[10]}$

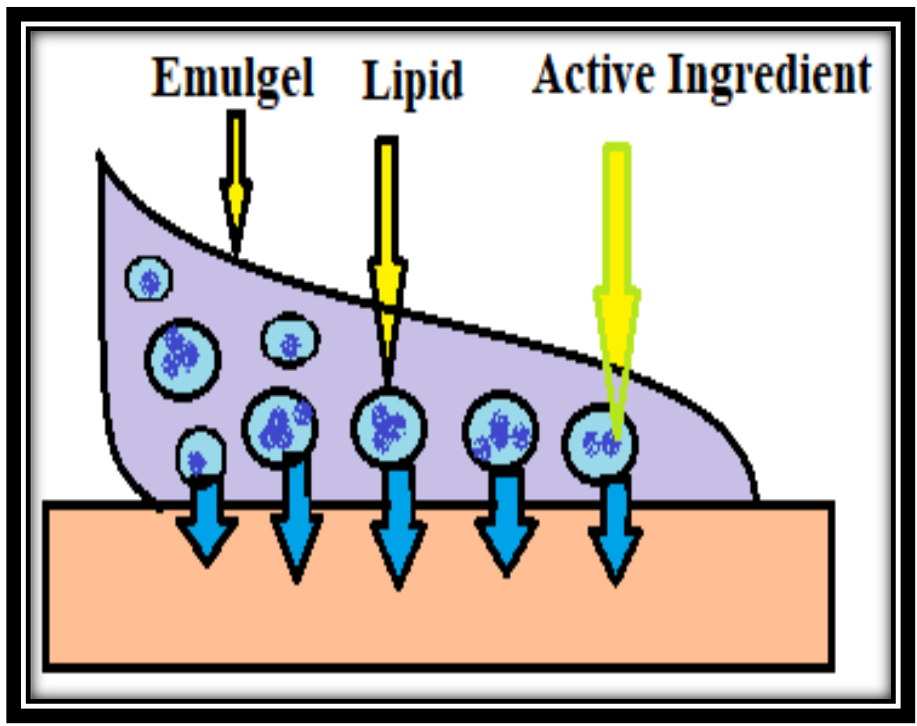

Figure No.4. Hypothesis of drug release

$>$ Biofriendly

$>$ Easily removable
$>$

$>$ Easily spreadable

$>$ Emollient

$>$ Grease less

$>$ Long shelf life

$>$ Nonstaining

$>$ Pleasing appearance

$>$ Thixotropic

$>$ Water soluble

\section{Hypothesis of Drug release mechanisms:}

\subsubsection{Factor affecting topical absorption of drugs} [9]

* Physiochemical factors Drug substances:

$>$ Concentration

$>$ Diffusion coefficient

$>$ Distribution in a stratum corneum

$>$ Excipients

$>$ Ionization- unionized drug are well absorbed

$>$ Molecular weight (<400 Dalton)

$>$ Penetration enhancer

$>$ Permeability coefficient

$>\mathrm{PH}$

$>$ Protein binding capacity

$>$ Solubility/polarity

$>$ Vehicle

$>$ Volatility

$>$ Water/lipid partition coefficient

* Physiological Factors

$>$ Blood flow

$>$ Density of hair follicles

$>$ Density of sweat glands

$>$ Duration of exposure

$>$ Hydration of skin

$>$ Inflammation of skin Site of application

$>$ Lipid content

$>$ Skin area dose (film thickness, concentration)

$>$ Skin $\mathrm{pH}$

$>$ Skin thickness

$>$ Total skin area in contact with vehicle

1.3.6 Advantages of Emulgel ${ }^{\text {[9] }}$

* Emulgel have pleasant appreance so patient acceptability is it Increased.

* It is easy to application of Emulgel termination of therapy.

* Emulgel improve bioavailability 
* Emulgel is advantageous in use of low dose that can be effective in comparison with other conventional semi solid preparation.

* It is Stable formulation in which surface interfacial tension resulting in increase in viscosity of aqueous phase, and become more stable than other topical formulation.

* Hydrophobic drug is incorporated in Emulgel by help of emulsion as the drug carrier than it is dispersed into gel.

* Emulgel provide the controlled effect which gives prolong effect of shorter half-life drug.

* It is Easy and cost effective formulation.

- Emulgel have better drug loading capacity than other novel approaches such as liposomes and niosomes.

* Penetration of skin is enhance because of hydrophilic and hydrophobic phase.

* Avoidance of first pass metabolism.

* Avoidance of gastrointestinal incompatibility.

* More selective to a specific site

- It proving better stability and good release of drug than only drugs into gel base.
* Suitability for self-medication.

\subsubsection{Disadvantages of Emulgel ${ }^{\text {[8]: }}$}

* Larger particle size drugs are not easy to absorb through the skin.

* Possibility of allergenic reactions.

- Skin irritation on contact dermatitis.

* Poor permeability of some drug through skin. 1.3.8 Applications of Emulgel ${ }^{[12]}$

* Hydrophobic drugs can be easily delivery by application of Emulgel.

* Emulgel provide good permeability, so criteria of low permeable antifungal application is increase.

* Emulgel provide good solubility, so Class II NSIDs Utilized as topical preparation at site of action.

* Good loading capacity: Because of vast network, it provide better loading capacity than other approaches like Noisome, Nanoparticle and liposomes

\subsubsection{Marketed formulations of Emulgel ${ }^{[8,13]}$}

Table No.3 Marketed Preparation of Emulgel.

\begin{tabular}{|l|l|ll|}
\hline Product Name & $\underline{\text { Drug }}$ & $\underline{\text { Manufacturer }}$ & \\
\hline Voltaren Emulgel & Diclofenac diethyl ammonium & Norvatis Pharma & \\
\hline Miconaz -H- Emulgel & $\begin{array}{l}\text { Miconazole nitrate, } \\
\text { Hydrocortisone. }\end{array}$ & $\begin{array}{l}\text { Medical } \\
\text { Pharmaceuticals }\end{array}$ & Union \\
& Diclofenac diethyl amine & Torrent Pharma & \\
\hline Diclofemax Emulgel & & &
\end{tabular}

\section{Evaluations}

Evaluation of Emulgel

\subsection{Physical Appearance and pH}

Determination

After the formulation, Emulgel was inspected visually to check its Consistency, colour, homogeneity and $\mathrm{pH}$. The $\mathrm{pH}$ values was measured by Preparing 1\% aqueous solutions of Emulgels were measured by a $\mathrm{pH}$ meter ${ }^{[14]}$.

\subsection{Drug Content Determination}

The drug content of Emulgel was measured by dissolving a known weight of the
Emulgel formulation (one gram) in $100 \mathrm{ml}$ methanol, appropriate dilutions were made and the resulting solution was filter. Absorbance was measured at $260 \mathrm{~nm}$ using UV- spectrophotometer. Slope and the intercept obtained by linear regression analysis of standard calibration curve and Drug content was calculated ${ }^{[14]}$.

\subsection{Rheological Studies}

The viscosity of Formulated Emulgel was determined at $25^{\circ} \mathrm{C}$ using a Brookfilled Viscometer. Viscosity was measured by using spindle ${ }^{[15]}$. 


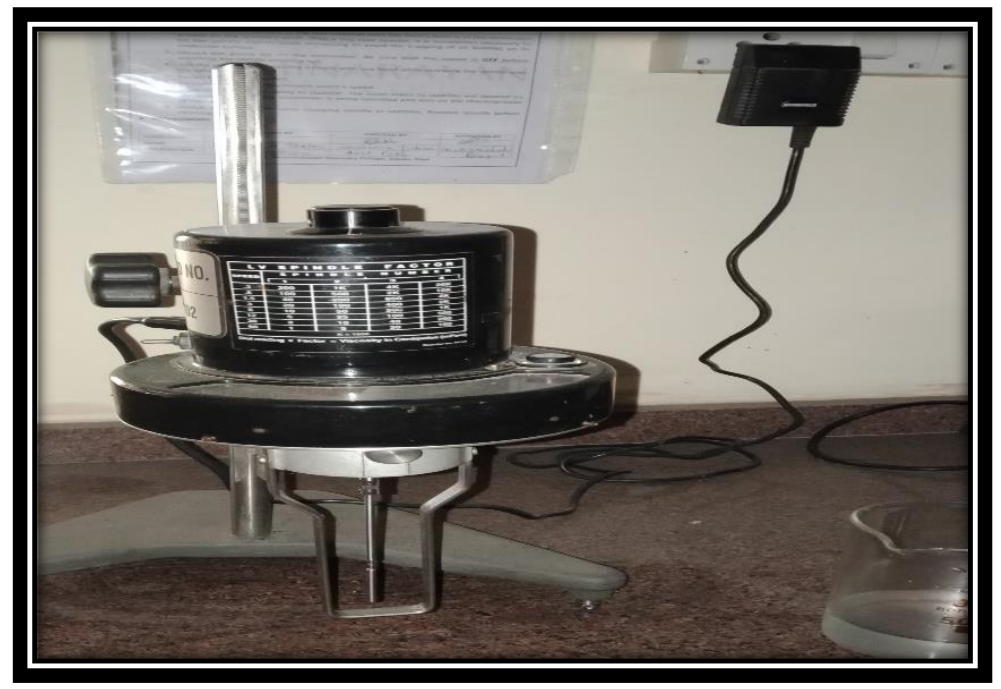

Figure No.5. Brookfield Viscometer

\subsection{Extrudability}

Extrudability of Emulgel is depend upon the quantity of Emulgel extruded from lacquered aluminium collapsible tube from
$0.5 \mathrm{~cm}$ in 10 seconds when weight in grams was applied. More the quantity extruded, better is Extrudability ${ }^{[16]}$.

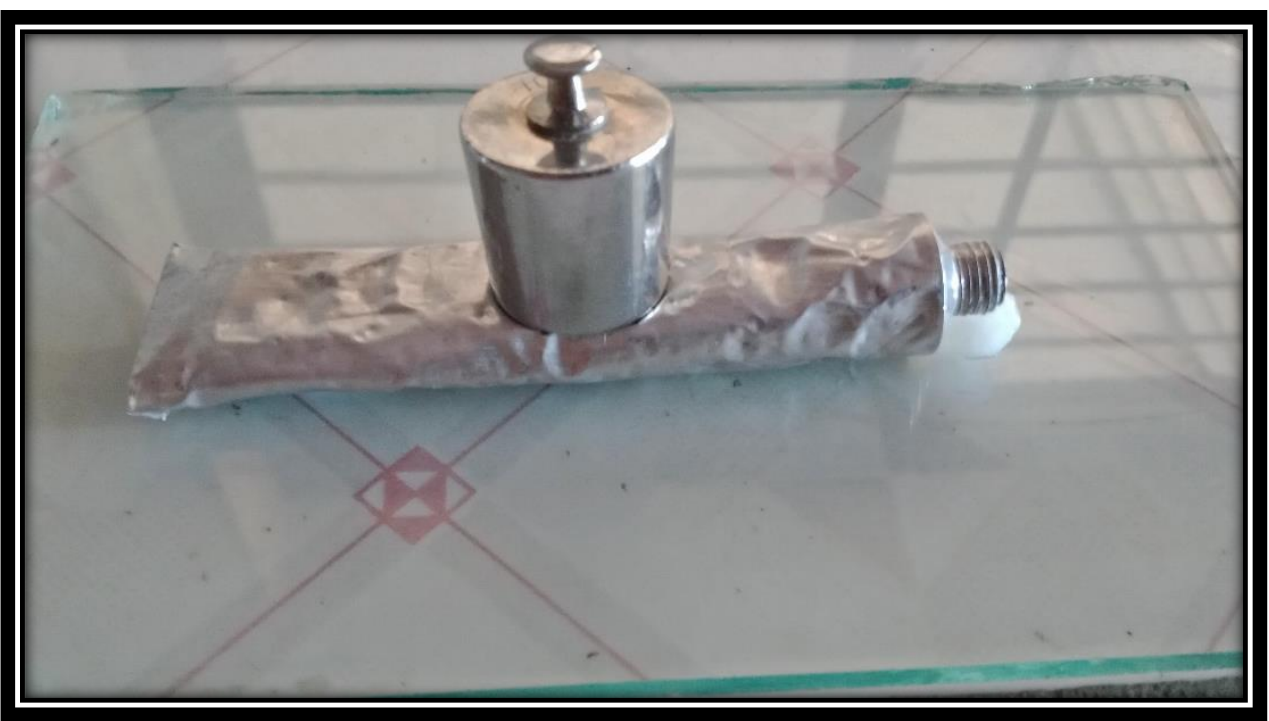

\section{Figure No.6. Extrudability measurement}

\subsection{Skin Irritation Test (Patch Test) ${ }^{[17]}$}

HET-CAM (Hen's Egg Test on the

Chorioallantoic Membrane)

Preparation of Test system:

* 9 days Fertile 50-60 g eggs was taken

* Out white cell was removed and moist inner membrane with $0.9 \%$ $(w / v)$ Nacl solution.

- Remove inner membrane before 20 minute to use.

Application of Test Sample:
Application of test substance directly to the CAM. Exposure of the CAM to the test substance for at least $300 \mathrm{sec}$.

The principle of the HET-CAM method was to observe existing vascular changes, such as hemorrhage, vascular lysis, and coagulation. The Sample of Emulgel was apply to the chorioallantoic membrane. The chorioallantoic membrane (CAM) is a complete network containing arteries, veins, and capillaries. Any vascular changes in 


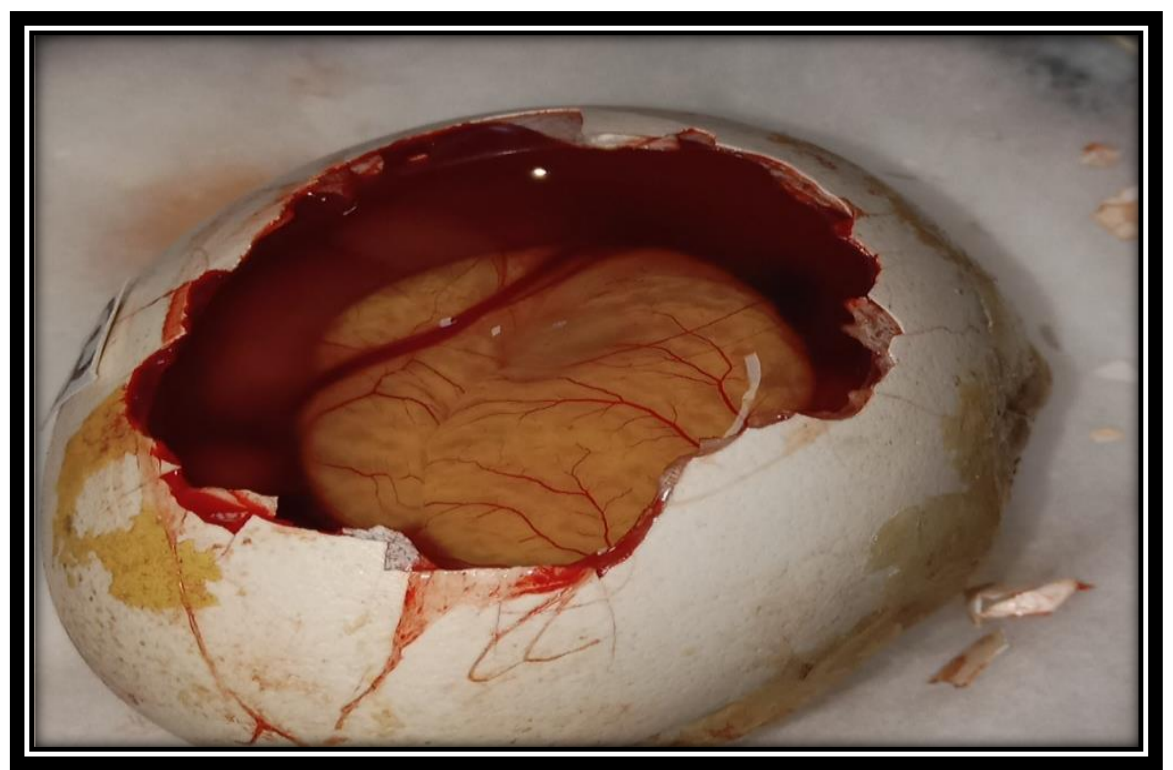

Figure No.7. HET-CAM (Hen's Egg Test on the Chorioallantoic Membrane)

\subsection{Spreading Coefficient}

Spreading coefficient was determined by apparatus Prepared by two glass slide. It consists of a wooden block, one end is attached to a pulley. On the basis of 'Slip' and 'Drag' characteristics of Emulgels Spreading coefficient was measured. . The excess of Emulgel (about $2 \mathrm{~g}$ ) sandwiched between two glass slides. A ground glass slide was fixed on the wooden block. The second glass slide is attach with the hook. Measured weight was placed in the pan attached to the pulley with the help of hook. The distance drag by top slide and time (in second) was noted. A shorter interval indicates better spreading coefficient ${ }^{[18]}$.

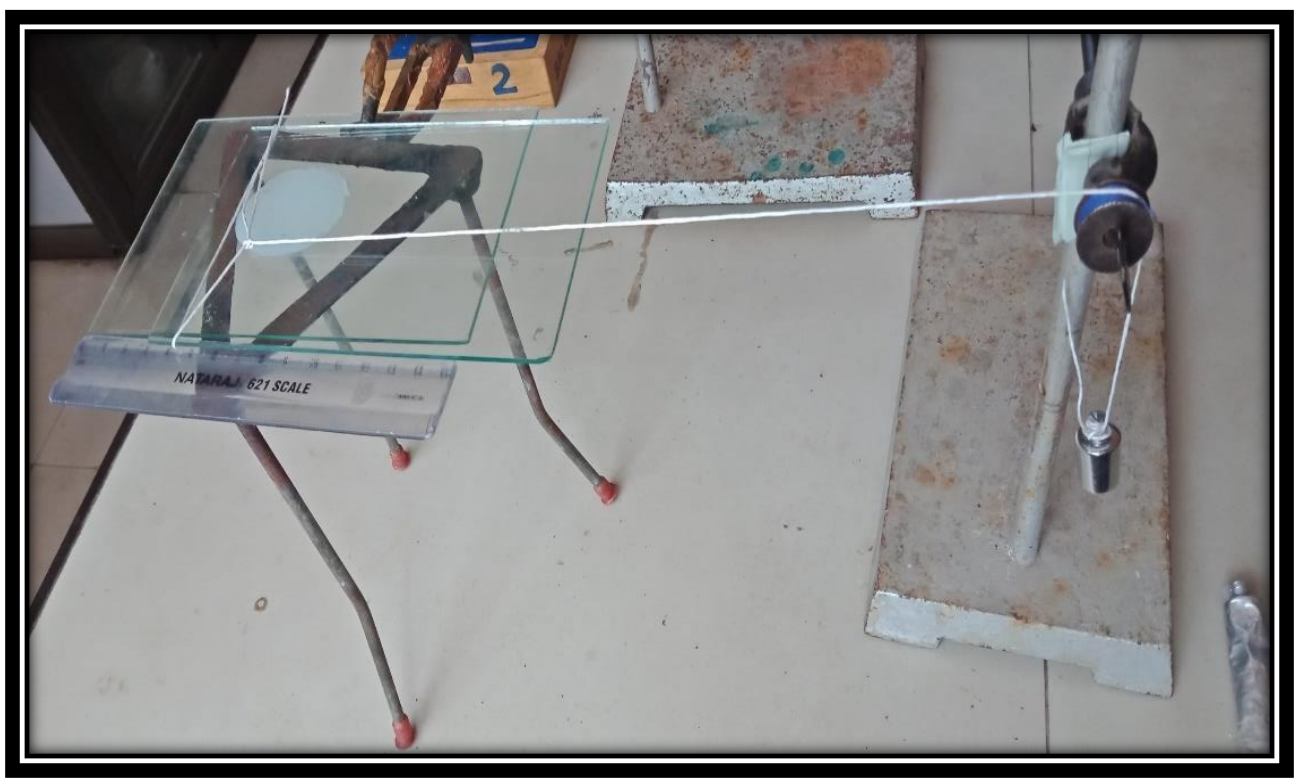

\subsection{In-Vitro Release Studies}

Figure No.8. Spreadability measurement 


\section{International Journal of Research in Advent Technology, Vol.7, No.3, March 2019 E-ISSN: 2321-9637 Available online at www.ijrat.org}

The release profile of Emulgel is determine by Franz diffusion cell. The cell consisted of two chambers, one is donor and another one is receptor compartment. Diffusion membrane is placed two compartment. The phosphate buffer solution $\mathrm{pH} 6.8$ (PBS) is use as diffusion medium. $1 \mathrm{gm}$. of the Emulgel containing drug was placed in the donor compartment separated from the receptor compartment by the egg membrane. The egg membrane was previously soaked for $24 \mathrm{hr}$. in PBS. The donor and receptor compartments were held together using a clamp. The whole assembly was fixed on a magnetic stirrer it was maintained at $37 \pm$ $0.5^{\circ} \mathrm{C}$ and stirred constantly at $50 \mathrm{rpm}$. Samples of 1 $\mathrm{mL}$ were collected at predetermined time intervals and analysed for drug content by UV Spectrophotometer at $\lambda$ max against blank ${ }^{[18]}$.

\subsection{Stability Studies}

The prepared Emulgel was packed in aluminium collapsible tube and subjected to stability studies at $25^{\circ} \mathrm{C} / 60 \%$ relative humidity (RH) and $40^{\circ} \mathrm{C} / 75 \%$ relative humidity (RH) for period of 3 months ${ }^{[19]}$. Samples were withdrawn at time intervals of 15 days and evaluated for physical appearance, rheological properties, drug content, $\mathrm{pH}$, and drug release ${ }^{[20]}$.

\section{CONCLUSION:}

Topical delivery of hydrophobic drug is challenging task. It is difficult to achieve delivery of drug from dosage due to its low solubility and low permeability. When hydrophobic drug is deliver as cream, ointment, lotions, emulsion the problem of stability and bioavailability is main issue. Only gel formulation is unable to deliver hydrophobic drugs. So the new concept of Emulgel is introduced in which emulsion is incorporated in gel has shown better delivery and good stability. In Emulgel, drug is incorporated in oil phase of emulsion and emulsion is better stabilize in the gel so, the combination of both of the phase provide the controlled release effect that improves the bioavailability of that drugs. Emulgel have number of advantages that will provide the big scope in future for the delivery of hydrophobic drug topically with more efficacy and less production cost. Oils with medicinal value provide the Synergistic effect to Emulgel.

\section{REFERENCE}

[1] Bhate, K; Williams, HC," Epidermilogy of acne vulgaris". The British Journal of Dermatology (review).2013 168(3):474-485.

[2] Gabriella fabbrocini,M,C. Annunziata,V.D' Arco, V.De Vita, G. Lodi,M.C Mauriello, F. Pastore, and G.Monfrecola "Acne Scars :
Pathogenesis, Classification and Treatment" 2010 page no : 1

[3] Sarah Taylor, MD, kristeen Cherney www.healthline.com

[4] https://www.ponds.com

[5] www.acnetreatment.net

[6] 6.Hyperpigmentation: types, diagrams and targeted treatment options http://onlinelibrary.wiley.com/doi/full/10.1111/jv d. 12048

[7] A. Ingber, Obstetric Dermatology A practical guide "hyperpigmentation and melasma" http:/www.springer.com/978-3-540-88398-2, 2009,-7-16.

[8] Shailendra Kumar Sah, Ashutosh Badola, Bipin Kumar Nayak," Emulgel: Magnifying the application of topical drug delivery ", Indian Journal of Pharmaceutical and Biological Research 2017, 25-31.

[9] K. P. Mohammed Haneefa, Sherry Easo2, P.V.Hafsa, Guru Prasad Mohanta, Chandini Nayar," Emulgel: An Advanced Review “, J. Pharm. Sci. \& Res. Vol.5 (12), 2013, 254 - 256.

[10] Sunil kumar yadav, Manoj kumar mishra, Anupamaa Tiwari, "Emulgel: A new approach for enhanced topical drug delivery" , Int J Curr Pharm Res Vol 9, Issue 1, 2017, 17

[11]S. B. Kute and R.B., "Emulsified gel A Novel approach for delivery of hydrophobic drugs: An overview ", Journal of Advanced Pharmacy Education \& Research Vol 3, Issue 4, 2013, 368370.

[12] Jaise Thomas, S Kuppuswamy, Anwara Aliyar Sahib, Ashinaa Benedict, "A Review on Emulgel as a Current Trend in Topical Drug Delivery System “, June 2017 Vol.:9, Issue:3 ,275-276.

[13] Abhijeet Ojha, Mini Ojha and N.V. Satheesh Madhav," Recent Advancement in Emulgel: A Novel Approach for Topical Drug Delivery" International Journal of Advances in Pharmaceutics 2017; 06(01), 21.

[14] Joshi Baihav, Singh Gurpreet, Rana A.C, Saini Seema,"Emulgel: A Comprehensive Review on the Recent Advances in Topical Drug Delivery." International Research Journal of Pharmacy, 2011, 2(11), Page No: 68.

[15] 15. Kumari, Aniket Singh, S. S. Saurabh, K. S. Rathore, R. Issarani, " Formulation and Evaluation of lycopene Emulgel", INDO AMERI CAN JORNAL OF PHARMACEUTICAL SCIENCES Volume2 (6), 2015, 1013-1027. 
International Journal of Research in Advent Technology, Vol.7, No.3, March 2019

E-ISSN: 2321-9637

Available online at www.ijrat.org

[16] Shahin M, Abdel HS, Hammad M, Mortada N. Drug development and industrial pharmacy,37(5):559-568, 2011.

[17] 17. Suryaprakash Vishvakarma, Anubhav Yadav, Formulation and Characterization of Citric Acid and Glycolic Acid Gel in Treatment of Pustules and Scars, 2019,480-490.

[18] 18. Shalaby S, Abd El-Aal S." Formulation and stability of chloramphenicol gel and emulgel", Bull Fac Pharm, 39:89-99, 2001.

[19] 19. Helal D, Rhman D, Abdel S, Nabarawi M. "Formulation and evaluation of fluconazole topical gel". Int. J. of pharmacy and pharmaceutical Sci., 4(5), 2012. Available: http://www.ijpps. Journal.com/vol. supp5/4593.pdf.

[20]20. ICH Harmonized Tripartite Guidelines, Stability Testing of New Drug Substances and Products. ICH Committee; 2003. 